\title{
PAIN PROCESSING IN FUNCTIONAL AND IDIOPATHIC DYSTONIA: AN EXPLORATORY STUDY
}

\begin{tabular}{|r|l|}
\hline Journal: & Movement Disorders \\
\hline Manuscript ID & MDS-17-1207.R2 \\
\hline Wiley - Manuscript type: & Research Article \\
\hline Complete List of Authors: & $\begin{array}{l}\text { Morgante, Francesca; Università di Messina, Dipartimento di Medicina } \\
\text { Clinica e Sperimentale } \\
\text { Matinella, Angela } \\
\text { Andrenelli, Elisa; Universita Politecnica delle Marche } \\
\text { Ricciardi, Lucia; St George's University of London } \\
\text { Allegra, Cosimo; Università di Messina } \\
\text { Terranova, Carmen; Università di Messina, Departimento di Medicina } \\
\text { Clinica e Sperimentale } \\
\text { Girlanda, Paolo; University of Messina } \\
\text { Tinazzi, Michele; University of Verona, Neurological and Movement } \\
\text { Sciences }\end{array}$ \\
\hline Keywords: & $\begin{array}{l}\text { functional movement disorders, psychogenic dystonia, cervical dystonia, } \\
\text { pain, emotions }\end{array}$ \\
\hline \multicolumn{2}{|c|}{} \\
\hline
\end{tabular}

SCHOLARONE ${ }^{\text {m }}$

Manuscripts 


\section{PAIN PROCESSING IN FUNCTIONAL AND IDIOPATHIC DYSTONIA: AN EXPLORATORY STUDY}

Francesca Morgante ${ }^{1,2}, \mathrm{MD}, \mathrm{PhD}$, Angela Matinella ${ }^{3}, \mathrm{MD}$, Elisa Andrenelli ${ }^{4}, \mathrm{MD}$, Lucia Ricciardi $^{2}, \mathrm{MD}, \mathrm{PhD}$, Cosimo Allegra ${ }^{1}, \mathrm{MD}$, Carmen Terranova ${ }^{1}, \mathrm{MD}, \mathrm{PhD}$, Paolo Girlanda ${ }^{1}, M D$, and Michele Tinazzi ${ }^{3}, M D$

${ }^{1}$ Department of Clinical and Experimental Medicine, University of Messina, Italy

${ }^{2}$ Institute of Molecular and Clinical Sciences, St George's University of London, London, United Kingdom

${ }^{3}$ Department of Neuroscience, Biomedicine and Movement, University of Verona, Italy

${ }^{4}$ Department of Experimental and Clinical Medicine, Università Politecnica delle Marche, Italy

Title (character count including spaces): 75

Running title: Pain processing in CD and F-Dys

Abstract count: 250; Text word count: 3134

Tables: 3; Figures: 2

Supplementary material: 1 table

References: 40

Key words: Functional movement disorders, psychogenic dystonia, cervical dystonia, pain, emotions

Financial disclosure related to research covered in this article: the authors do not have any funding source or any conflict of interest related to the research covered in the article.

\section{Correspondence to:}

Dr Francesca Morgante

Department of Clinical and Experimental Medicine, University of Messina, Italy 
Morgante et al, Pain processing in CD and F-Dys

Email: fmorgante@gmail.com

\section{ABSTRACT \\ Background}

Pain is often experienced by patients with functional dystonia and idiopathic cervical dystonia and it is likely to be underlined by different neural mechanisms.

\section{Objective}

In this exploratory study, we tested the sensory-discriminative and cognitive-emotional component of pain in patients with functional and idiopathic dystonia.

\section{Methods}

Ten patients with idiopathic cervical dystonia, 12 patients with functional dystonia and 16 age- and gender matched healthy controls underwent psychophysical testing of tactile and pain thresholds and pain tolerance. We delivered electrical pulses of increasing intensity to the index finger of each hand and the halluces of each foot. Pain threshold and Pain tolerance were respectively defined as: 1) the intensity at which sensation changed from unpainful to faintly painfull and 2) the intensity at which painful sensation was intolerable.

\section{Results}

No differences were found between the three groups for tactile and pain thresholds assessed in both hands and feet. Pain tolerance was significantly increased in all body district only in functional dystonia. Patients with continuous functional dystonia had higher pain tolerance compared to subjects with paroxysmal functional dystonia and idiopathic cervical dystonia. Spearman Rank Correlation did not demonstrate any correlation between pain tolerance and pain scores, depression, anxiety, disease duration and motor disability in both groups.

\section{Conclusions}

Patients with functional dystonia have a dissociation between the sensory-discriminative and cognitive-emotional component of pain, as revealed by normal pain thresholds and increased pain tolerance. An abnormal connectivity between the motor and the limbic system might account for abnormal pain processing in functional dystonia. 
Morgante et al, Pain processing in CD and F-Dys

\section{INTRODUCTION}

Functional neurological disorders (FND) have been recently better defined at pathophysiological level and distinguished from symptoms that are intentionally produced, such as malingering and factitious disorder ${ }^{1}$. FND are a source of major neurological disability, especially when they produce a motor disturbance, such as in Functional Dystonia (F-Dys). Patients affected by F-Dys often experience pain, which is sometimes disproportionate to motor symptoms and it frequently occurs in body segments not affected by involuntary movements ${ }^{2}$. Subjects with idiopathic cervical dystonia also experience painful sensations, especially in affected body parts ${ }^{3}$.

The large brain network accessed during nociceptive processing is now commonly referred to as the "pain matrix" and it includes lateral (sensory-discriminatory) and medial (affective-cognitive) neuroanatomical components ${ }^{4}$. The lateral pathway projects to lateral thalamus and then to primary and secondary somatosensory areas, while the medial pathway projects to medial thalamic nuclei and limbic structures, such as the anterior cingulate cortex and the insular cortex. Sensory-discriminative and cognitive-affective aspects of pain may be selectively assessed by simple and reliable psycophysical parameters, such as the sensory thresholds. In particular, the pain threshold (P-Th) evaluates the sensory-discriminative component of pain, whereas the pain tolerance $(P$ tol) refers to the psychological perception of pain, a complex balance between cognitive and affective functions ${ }^{5}$. The contribution of the somatosensory system is well-known in idiopathic dystonia (including $C D)^{6}$ and it was recently demonstrated in functional dystonia (F-Dys), by testing of tactile temporal discrimination thresholds ${ }^{7}$. Yet, experimental data on pain perception are missing in both F-Dys and idiopathic cervical dystonia, which is often associated to pain. Only one study employing laser evoked potentials has revealed that the function of nociceptive pathways in cervical dystonia is comparable to healthy subjects ${ }^{8}$.

Based on the evidence that in F-Dys there is an abnormal connectivity between motor and limbic areas $^{9}$, we hypothesized an alteration of the cognitive-emotional component of pain in F-Dys. On the other hand, patients with idiopathic dystonia have an abnormal temporal processing of somatosensory stimuli $^{10}$ and a distorsion of cortical maps in the somatosensory cortex ${ }^{11}$, which might determine an alteration of the sensory-discriminatory component of pain. Given these premises, in the present study we aimed to assess the sensory-discriminative and cognitive-emotional components of pain in idiopathic cervical 
Morgante et al, Pain processing in $C D$ and F-Dys

dystonia and F-Dys, testing pain thresholds and pain tolerance in affected and unaffected body segments.

\section{METHODS}

We enrolled 10 patients with idiopathic cervical dystonia (CD), 12 patients with clinically definite $\mathrm{F}$-Dys ${ }^{12}$ and 16 healthy controls $(\mathrm{HC})$ (13 females, 3 males; mean age = $34.6 \pm 10.8$ years).

The diagnosis of idiopathic dystonia was based on the Movement Disorders Society recommendations $^{13}$ and the diagnosis of F-Dys on Gupta-Lang criteria ${ }^{12}$. Exclusion criteria were presence of clinically relevant cognitive impairment (MMSE <24), diabetes mellitus, tendon areflexia and polyneuropathy by nerve conduction studies. Severity of dystonia was evaluated with the Burke-Fahn-Marsden scale ${ }^{14}$ in all patients with F-Dys and CD. We also employed the Psychogenic Movement Disorders Rating Scale (PMDRS) ${ }^{15}$ in F-dys. In each patient, we retrieved demographical and clinical features (age at onset, disease duration, affected body districts).

Pain was assessed using the pain score of the Toronto Western Spasmodic Torticollis Rating Scale (TWSTRS) ${ }^{16}$. The TWSTRS includes pain scores for severity (0-10), duration (0-5) and pain-related disability (0-5). Moreover, all the different painful body segments were recorded, including those without dystonia. Depression and anxiety were evaluated in patients and controls with Hamilton depression Rating Scale (HAM-D) and Hamilton Anxiety Rating Scale (HAM-A). In all patients treated with botulinum toxin (BoNT), the experiment was carried out at least 3 months after the injection.

Tactile and pain thresholds were determined by the method of limits, according to a previous published protocol ${ }^{5,17}$. The stimulus consisted of a square wave electrical pulse of $0.2 \mathrm{~ms}$ delivered by a current stimulator (Digitimer D360, Digitimer Ltd, UK) through $\mathrm{AgCl}$ surface skin ring electrodes. The anode was located $1.5 \mathrm{~cm}$ distally from the cathode. Hands and feet were tested separately in a random order across patients. Electrical stimuli of increasing intensity were delivered to the little finger and big toe of both sides. In brief, the lowest intensity of stimulus $(0.5 \mathrm{~mA})$ was increased by $0.5 \mathrm{~mA}$ steps until the subject perceived the electrical stimulus (tactile threshold; T-Th). When the subject perceived the electrical stimulus, we delivered decreasing stimuli with minimum difference in intensity $(0.1 \mathrm{~mA})$ until the correct T-Th was determined. We considered as exact T-Th the value to which the subject gave the same affirmative answer after four consecutive stimuli at the same intensity. Then, the intensity of electrical stimulus was 
increased by $0.5 \mathrm{~mA}$ steps until the subject reported a change in sensation from unpainful to "faintly painful" (pain threshold, P-Th). The patient was asked to point out his pain intensity on a Visual Analogue Scale (VAS) line ranging from 0 to 10 . Finally, the intensity of electrical stimulus was increased by $1 \mathrm{~mA}$ steps until the subject reported an "intolerable" painful sensation (pain tolerance, P-Tol). If the subject did not report an intolerable pain sensation with $99 \mathrm{~mA}$ at $0.2 \mathrm{~ms}$ of stimulus duration, we increased the stimulus duration to $0.5 \mathrm{~ms}$ and $1 \mathrm{sec}$ ( 3 subjects with F-Dys described in the results).

In order to avoid the pain-modulating effects of BoNT injections, the experiments were performed with a distance after the last botulinum treatment of at least 3 months.

The study was approved by the ethic committee of University of Verona and conformed to the Declaration of Helsinki. All patients gave their written informed consent prior to participation.

\section{STATISTICAL ANALYSIS}

Normal distribution was checked using the Kolmogorov-Smirnov test. In case of deviation from normality, non-parametric tests were used.

Kruskal-Wallis test was employed to compare HC, F-Dys and CD for age and education level. Disease duration in F-Dys and CD was compared using the Mann-Whitney U test.

Differences in T-Th, P-Th and P-Tol among the 3 groups of subjects were explored by repeated measures analysis of variance (R-ANOVA) with "group" as between subjects factor (3 levels: HC, F-Dys and CD) and "side" (two levels: right, left) as within-subjects factor. The second aim of our study was to understand if pain thresholds were different in patients with F-Dys according to the temporal pattern of dystonic symptoms, namely patients with persistent versus paroxysmal symptoms. Accordingly, for each psychophysical variable (T-Th, P-Th and P-Tol), we run a separate R-ANOVA with "group" as between subjects factor (three levels: continuous F-Dys, paroxysmal F-Dys, CD) and "side" (two levels: right, left) as within-subjects factor.

Conditional on a significant F-value, post-hoc unpaired t-tests were performed to demonstrate differences between groups in each body site. Correction for multiple comparisons was not conducted given the exploratory nature of the study.

In F-Dys and CD, correlational analysis was performed by Spearman rank-correlation using P-tol values averaged between the right and left hand or foot. We verified whether $\mathrm{P}$-Tol values were correlated to age, age at onset, disease duration, BFM scale, pain scores of TWSTRS (severity, duration, disability due to pain), HAM-D and HAM-A. 
Morgante et al, Pain processing in $C D$ and F-Dys

Significance level was set at $p \leq 0.05$. Unless otherwise stated, data are given as mean \pm standard deviation (SD).

\section{RESULTS}

Distribution of gender was comparable among the 3 groups (G-squared p-value $=0.6$ ). Kruskall-Wallis analysis did not disclose any difference in age $(p=0.08)$, although patients with CD were older compared to $\mathrm{HC}(p=0.01)$. Age was comparable between $\mathrm{HC}$ and $\mathrm{F}$ dys $(p=0.5)$ and tended to be higher in CD compared to F-Dys $(p=0.06)$. All patients with CD and 4 out of 12 patients with F-Dys have been chronically treated with BoNT, performed at least 3 months before the experiment. Supplementary table online shows details on each patient's oral medications.

Tables 1 reports the features of patients with F-Dys and CD. At the time of the assessment, the two groups were comparable for age of onset ( $F$-Dys $=27.3 \pm 12.1$ years, $C D=37.5 \pm 15.8 ; p=0.5)$, disease duration $(p=0.7)$, level of anxiety $(p=0.9)$ and depression $(p=0.8)$. Among F-Dys, 4 patients had an exclusive involvement of facial muscles and the movement disorder was paroxysmal in 6 patients. The mean PMDRS score was 23.3+2.8. CD patients had isolated cervical dystonia, except for two patients who also presented writer's cramp.

The values of S-Th, P-Th and P-Tol in HC, CD, F-Dys recorded from the right and left hand and foot are displayed in table 2. For both S-Th and P-Th, R-ANOVA did not show any effect of the factor "group". No effect of group was found for pain intensity at pain threshold level by VAS (hands: $F_{2,35}=0.56, p=0.57$; feet: $F_{2,35}=1.31, p=0.29$ ). An effect of the factor "group" was found for P-Tol in both the hands $\left(F_{2,35}=3.766, p=0.033\right)$ and the feet $\left(F_{2,35}=3.986, p=0.028\right)$. No effect of the factor "side" (hands: $F_{2,35}=0.68, p=0.41$; feet: $F_{2,35}=0.16, p=0.70$ ) nor an interaction "side*group" (hand: $F_{2,35}=1.27, p=0.29$; feet: $F_{2,35}=0.02, p=0.99$ ) was found. Post-hoc analysis by unpaired t-test revealed a higher PTol in F-Dys compared to HC and CD, in the upper and lower limbs; no differences of PTol were found between CD and HC.

Figure 1 shows the individual values for P-Th and P-Tol in the 3 groups of subjects. For PTol, we had to increase the stimulus duration in 3 subjects with F-Dys who reported an unbearable stimulation at $0.5 \mathrm{~ms}$ (2 subjects for the right hand, right foot, left foot; 1 subject for the left hand) and 1 second (1 subject for all body districts.). As it was not possible to account for stimulus duration in the analysis only for 3 subjects, a value of 100 
$\mathrm{mA}$ (corresponding to the maximal allowed stimulation with $0.2 \mathrm{~ms}$ pulse width) was set as P-Tol in these subjects.

To understand if the increased P-Tol was influenced by the temporal course of functional dystonic manifestation (persistent or paroxysmal), we conducted a further analysis comparing CD patients to F-Dys with persistent (continuous F-Dys) and paroxysmal (paroxysmal F-Dys) functional symptoms. There was no main effect of the factor "group" both for S-Th in hands $\left(F_{2,19}=1.41, p=0.27\right)$ and feet $\left(F_{2,19}=2.11, p=0.16\right)$ and P-Th in hands $\left(F_{2,19}=0.82, p=0.45\right)$ and feet $\left(F_{2,19}=0.99, p=0.39\right)$. Neither a significant effect of "side" or an interaction "side* group" were found for S-Th and P-Th in the hands and feet.

For P-Tol, we found a "group" effect $\left(F_{2,19}=9.89\right.$; $\left.p=0.001\right)$, but neither an effect of "side" $\left(F_{2,19}=1.63 ; p=0.21\right)$ nor an interaction "side ${ }^{*}$ group" $\left(F_{2,19}=0.4 ; p=0.67\right)$. This effect was determined by a higher P-Tol in both hands and feet of F-Dys with continuous F-Dys compared to paroxysmal F-Dys and CD (Figure 2). Similar results for P-Tol were disclosed also in the lower limbs, as revealed by a main effect of "group" $\left(F_{2,19}=4.15 ; p=0.03\right)$ but neither an effect of "side" $\left(F_{2,19}=0.06 ; p=0.81\right)$ nor an interaction "side*group" $\left(F_{2,19}=0.01\right.$; $\mathrm{p}=0.98$ ) (Figure 2).

In CD and F-Dys, Spearman Rank Correlation did not show any correlation between P-tol in hands and feet with age, disease duration, pain scores of the TWSTRS, BFM, HDRS, HARS (Table 3). Only HDRS was correlated to pain severity score of the TWSTRS in FDys.

\section{DISCUSSION}

Painful sensory modalities have been poorly examined in idiopathic cervical dystonia and functional dystonia, two conditions characterized by pain, likely to be underlined by a different mechanism. Tactile and pain thresholds were comparable between F-Dys, CD and $\mathrm{HC}$, whereas pain tolerance was higher in F-Dys. This increase occured in both the upper and lower limbs only in subjects with persistent F-Dys, as paroxysmal F-Dys and idiopathic cervical dystonia had comparable pain tolerance.

Pain is a frequent feature associated to cervical dystonia, occurring in up to $88.9 \%$ of patients naïve to BoNT and being correlated with severity of dystonic symptoms ${ }^{3}$. Whether pain in cervical dystonia is related to chronic muscular contraction or is generated by an alteration of transmission and processing of nociceptive stimuli has been matter of debate for a long time ${ }^{8,18-20}$. Several sensory modalities have been explored in idiopathic isolated dystonia and one of the most frequently reported alteration is the prolonged temporal 
tactile discrimination threshold, which is a common feature to different types of dystonia, regardless the affected body segment ${ }^{21,22}$. Pain is a sensory modality, which is transmitted by $A-\delta$ and $C$ fibers and can be explored using a variety of stimuli, including pain thresholds evoked by thermal sensation and mechanical pressure. Electrical stimulation at high intensity as per pain threshold testing can stimulate small diameter, high threshold cutaneous afferents (A-delta) and even C-fibers ${ }^{23}$. When considering perception of mechanical painful stimuli, two studies on pain-pressure thresholds were conducted in CD with opposite results. An earlier study found reduced pain-pressure thresholds in 9 patients with CD (6 of them never treated with BoNT) compared to 5 healthy subjects ${ }^{19}$. However, when assessing a larger sample of 39 patients with CD, Kutvonen and coworkers found normal pain-pressure thresholds ${ }^{20}$. The normality of pain thresholds and tolerance in our CD sample parallels these early findings, obtained with pressure painful stimuli and supports the view that at least cutaneous nociceptive pathways are normal in patients with idiopathic CD chronically treated with BoNT. Overall, they are in keeping with the evidence that the amplitude of N2/P2 at laser evoked potential is comparable between CD and healthy subjects, regardless of stimulating a painful or painless area in dystonia ${ }^{8}$.

The abnormality of pain tolerance only in patients with persistent dystonic functional symptoms supports the recent view that there are distinct phenotypes among F-Dys ${ }^{24}$. However, data on pathophysiological differences among F-Dys phenotypes are not available. The increase of pain tolerance together with the normality of pain threshold, suggests a dissociation between the sensory-discriminative and cognitive-affective components of pain in persistent F-Dys. These two dimensions of pain are regulated by separate but parallel neural systems, respectively the lateral pain system (sensorydiscriminative dimension of pain) and the medial pain system (cognitive-affective dimension of pain $)^{25}$. The lateral system projects to the primary somatosensory cortex through the lateral thalamic nuclei whereas the medial system projects to several brain regions, including the cingulate cortex and limbic system, via the medial medial thalamic nuclei. The two systems are functionally segregated and can be separately assessed by applying nociceptive stimuli of different intensities ${ }^{26}$. The dissociation of the two systems in F-dys is in keeping with two previous studies, reporting increased pain tolerance and normal sensory-discriminative thresholds in patients with multisomatoform disorders ${ }^{27,} 28$. The category "somatoform" refers to DSM-IV TR, which included in this entity somatization and conversion disorder, pain, hypochondria and body dysmorphic disorder. Clinical 
features of subjects in these previous reports were not specified, therefore it is not possible to ascertain whether any functional movement disorder and more specifically functional dystonia was included. Nevertheless, both these studies reported averaged values from the right and the left hand and did not assess lower limbs.

Two psychological features of patients with FND might explain the increased pain tolerance in F-Dys: 1) the higher frequency of alexithymia, which refers to the inability to identify one's own emotions at a cognitive level ${ }^{29}$; 2) the lower interoceptive awareness, which is predictive of their tendency to focus on the external features of their body ${ }^{30}$. A similar reduced interoceptive sensitivity was also found in somatoform patients who disclosed increased pressure-pain tolerance ${ }^{27}$.

A hypothesis to explain our findings in F-Dys is that the increased pain tolerance might be caused by abnormalities in limbic areas involved in emotion and pain processing (anterior cingulate cortex) and implicated in assigning emotional salience (amygdala, anterior insula, and posterior cingulate cortex). Indeed, abnormalities in areas involved in emotion recognition and processing has been shown in patients with FND $^{31-33}$. Moreover, FND subjects have reduced activity and lower connectivity of the right temporoparietal junction (an area involved in generating an appropriate sensory prediction signal) with sensorimotor and limbic regions, such as the anterior cingulate cortex and right ventral striatum $^{32}$. Noteworthy, deep brain stimulation or lesioning of the anterior cingulate cortex are able to decrease the affective response to noxious stimuli and are employed to treat major depression or intractable pain ${ }^{34}$. This hypothesis needs confirmation by further studies emplying functional neuroimaging with pain stimuli tasks as well ass assessment of emotional processing and alexithymia.

When interpreting our results, we should also consider recent theories on FND ${ }^{35}$ postulating that two important mechanisms for generating these abnormal movements are self-focus attention and 'brain-expectations'. In fact, strong "top down" influences, such "prior beliefs" would tend to modify any "bottom up" sensory information. Moreover, excessive attention towards the body ${ }^{36}$ might underlie the decrease in externally directed attention. These could influence the cognitive appraisal of pain tolerance. However, this mechanism would not entirely explain the dissociation between pain threshold and tolerance in F-Dys.

Finally, chronic functional dystonia might have determined a reorganization of sensory areas, as it has been demonstrated in complex pain regional syndrome type I, a condition that should be included into the functional symptoms spectrum based on clinical and 
Morgante et al, Pain processing in $C D$ and F-Dys

neurophysiological evidence ${ }^{37}$. When dealing with pain it is also fundamental to discuss the role of emotions and mood on pain processing. Indeed, decreased pain thresholds and pain tolerances in Parkinson's disease were correlated to severity of depressive symptoms $^{5}$ and a similar association was found in patients with major depressive disorder ${ }^{17}$. Regarding the relationship between anxiety and pain tolerance, the literature has been controversial on this topic, with reports of decreased pain tolerance in posttraumatic stress disorder ${ }^{38}$ or lack of correlation between anxiety and pain tolerance in patients with juvenile fibromyalgia ${ }^{38}$. Accordingly, we screened our sample for depression and anxiety and we could not find any correlation with pain tolerance, which also had an inverse pattern in F-Dys compared to subjects with major depression. Yet, we need to recognize that we did not employ measures of state anxiety and depression that have been found to modulate pain perception.

We recognize that the small sample size of this exploratory study represents an important limitation, given the inter-subject variability of psychophysical data, especially in the lower limbs. Even though we could not find any correlation between age and pain tolerance in FDys, CD and HC, the role of age on pain tolerance should be specifically addressed in future studies, as it has been done for parameters of somatosensory processing, such as tactile temporal discrimination thresholds ${ }^{39,40}$. Moreover, objective measures such as pain evoked potentials or galvanic skin response should be added to P-Tol assessment in future studies investigating pain processing in functional dystonia. Chronic treatment with botulinum toxin and oral medication might also have interfered with pain thresholds testing, although they were equally distributed between patients' groups.

In conclusion, we reported a dissociation between the discriminative and affective dimension of pain in patients with persisten F-Dys, documented by a marked increase in pain tolerance in all body parts. Our data shed a light on the dissociation between pain perception and its emotional processing in patients with functional dystonia, which might be used to develop novel rehabilitation protocols, given the profound disability caused by pain and its negative impact on the selection for current physiotherapy protocols ${ }^{41}$. 


\section{LEGEND TO FIGURES}

Figure 1. Individual values for pain threshold and pain tolerance in functional dystonia (FDys) compared to idiopathic cervical dystonia (CD) and healthy controls (HC). CD = cervical dystonia; F-Dys= functional dystonia; $\mathrm{HC}=$ healthy controls; $\mathrm{PT}=$ pain threshold; $\mathrm{P}$-Tol = Pain tolerance. . Dotted and dashed lines respectively refer to the mean and standard deviation across the 3 groups.

Figure 2. Pain tolerance was significantly increased in the both hands of subjects with persistent functional dystonia (F-Dys-C) compared to paroxysmal functional dystonia (FDys-P) and cervical dystonia (CD). Pain tolerance was increased in both feet of F-Dys-C compared to CD; the difference between F-Dys-C and F-Dys-P did not reach statistical significance when considering P-Tol in both feet. 
Morgante et al, Pain processing in $C D$ and F-Dys

\section{REFERENCES}

1. Edwards MJ, Stone J, Lang AE. From psychogenic movement disorder to functional movement disorder: it's time to change the name. Mov Disord 2014;29:849-852.

2. Ganos C, Edwards MJ, Bhatia KP. The Phenomenology of Functional (Psychogenic) Dystonia. Movement Disorders Clinical Practice 2014;1:36-44.

3. Charles PD, Adler CH, Stacy M, et al. Cervical dystonia and pain: characteristics and treatment patterns from CD PROBE (Cervical Dystonia Patient Registry for Observation of OnabotulinumtoxinA Efficacy). J Neurol 2014;261:1309-1319.

4. Tracey I, Mantyh PW. The cerebral signature for pain perception and its modulation. Neuron 2007;55:377-391.

5. Zambito Marsala S, Tinazzi M, Vitaliani R, et al. Spontaneous pain, pain threshold, and pain tolerance in Parkinson's disease. J Neurol 2011;258:627-633.

6. Scontrini A, Conte A, Defazio G, et al. Somatosensory temporal discrimination in patients with primary focal dystonia. JNeurolNeurosurgPsychiatry 2009;80:1315-1319.

7. Morgante F, Tinazzi M, Squintani G, et al. Abnormal tactile temporal discrimination in psychogenic dystonia. Neurology 2011;77:1191-1197.

8. Tinazzi M, Valeriani M, Squintani G, et al. Nociceptive pathway function is normal in cervical dystonia: a study using laser-evoked potentials. J Neurol 2012;259:2060-2066.

9. Voon V, Brezing C, Gallea C, et al. Emotional stimuli and motor conversion disorder. Brain 2010;133:1526-1536.

10. Bradley D, Whelan R, Walsh R, et al. Temporal discrimination threshold: VBM evidence for an endophenotype in adult onset primary torsion dystonia. Brain 2009;132:2327-2335. 11. Meunier S, Garnero L, Ducorps A, et al. Human brain mapping in dystonia reveals both endophenotypic traits and adaptive reorganization. AnnNeurol 2001;50:521-527.

12. Gupta A, Lang AE. Psychogenic movement disorders. CurrOpinNeurol 2009;22:430436.

13. Albanese A, Bhatia K, Bressman SB, et al. Phenomenology and classification of dystonia: a consensus update. Mov Disord 2013;28:863-873.

14. Burke RE, Fahn S, Marsden CD, Bressman SB, Moskowitz C, Friedman J. Validity and reliability of a rating scale for the primary torsion dystonias. Neurology 1985;35:73-77. 15. Hinson VK, Cubo E, Comella CL, Goetz CG, Leurgans S. Rating scale for psychogenic movement disorders: scale development and clinimetric testing. Mov Disord 2005;20:15921597.

16. Comella CL, Stebbins GT, Goetz CG, Chmura TA, Bressman SB, Lang AE. Teaching tape for the motor section of the Toronto Western Spasmodic Torticollis Scale. Mov Disord 1997;12:570-575.

17. Zambito Marsala S, Pistacchi M, Tocco P, et al. Pain perception in major depressive disorder: a neurophysiological case-control study. J Neurol Sci 2015;357:19-21.

18. Stamelou M, Edwards MJ, Hallett M, Bhatia KP. The non-motor syndrome of primary dystonia: clinical and pathophysiological implications. Brain 2012;135:1668-1681.

19. Lobbezoo F, Tanguay R, Thon MT, Lavigne GJ. Pain perception in idiopathic cervical dystonia (spasmodic torticollis). Pain 1996;67:483-491.

20. Kutvonen O, Dastidar P, Nurmikko T. Pain in spasmodic torticollis. Pain 1997;69:279-

286.

21. Bradley D, Whelan R, Walsh R, et al. Comparing endophenotypes in adult-onset primary torsion dystonia. Mov Disord 2010;25:84-90.

22. Tinazzi M, Fiorio M, Fiaschi A, Rothwell JC, Bhatia KP. Sensory functions in dystonia: insights from behavioral studies. Mov Disord 2009;24:1427-1436. 
23. Lundberg LE, Jorum E, Holm E, Torebjork HE. Intra-neural electrical stimulation of cutaneous nociceptive fibres in humans: effects of different pulse patterns on magnitude of pain. Acta Physiol Scand 1992;146:41-48.

24. Petrovic IN, Tomic A, Voncina MM, Pesic D, Kostic VS. Characteristics of two distinct clinical phenotypes of functional (psychogenic) dystonia: follow-up study. J Neurol 2018;265:82-88.

25. Garland EL. Pain processing in the human nervous system: a selective review of nociceptive and biobehavioral pathways. Prim Care 2012;39:561-571.

26. Benedetti F, Vighetti S, Ricco C, et al. Pain threshold and tolerance in Alzheimer's disease. Pain 1999;80:377-382.

27. Weiss S, Sack M, Henningsen P, Pollatos O. On the interaction of self-regulation, interoception and pain perception. Psychopathology 2014;47:377-382.

28. Pollatos 0 , Dietel A, Herbert BM, et al. Blunted autonomic reactivity and increased pain tolerance in somatoform patients. Pain 2011;152:2157-2164.

29. Demartini B, Petrochilos P, Ricciardi L, Price G, Edwards MJ, Joyce E. The role of alexithymia in the development of functional motor symptoms (conversion disorder). J Neurol Neurosurg Psychiatry 2014;85:1132-1137.

30. Ricciardi L, Demartini B, Crucianelli L, Krahe C, Edwards MJ, Fotopoulou A. Interoceptive awareness in patients with functional neurological symptoms. Biol Psychol 2016;113:68-74.

31. Aybek S, Nicholson TR, O'Daly 0, Zelaya F, Kanaan RA, David AS. Emotion-motion interactions in conversion disorder: an FMRI study. PLoS One 2015;10:e0123273.

32. Voon V, Gallea C, Hattori N, Bruno M, Ekanayake V, Hallett M. The involuntary nature of conversion disorder. Neurology 2010;74:223-228.

33. Voon V, Brezing C, Gallea C, Hallett M. Aberrant supplementary motor complex and limbic activity during motor preparation in motor conversion disorder. Mov Disord 2011;26:2396-2403.

34. Boccard SGJ, Prangnell SJ, Pycroft L, et al. Long-Term Results of Deep Brain Stimulation of the Anterior Cingulate Cortex for Neuropathic Pain. World Neurosurg 2017;106:625-637. 35. Edwards MJ, Adams RA, Brown H, Parees I, Friston KJ. A Bayesian account of 'hysteria'. Brain 2012;135:3495-3512.

36. Edwards MJ, Fotopoulou A, Parees I. Neurobiology of functional (psychogenic) movement disorders. Curr Opin Neurol 2013;26:442-447.

37. Morgante F, Naro A, Terranova C, et al. Normal sensorimotor plasticity in complex regional pain syndrome with fixed posture of the hand. Mov Disord 2017;32:149-157. 38. King CD, Jastrowski Mano KE, Barnett KA, Pfeiffer M, Ting TV, Kashikar-Zuck S. Pressure Pain Threshold and Anxiety in Adolescent Females With and Without Juvenile Fibromyalgia: A Pilot Study. Clin J Pain 2017;33:620-626.

39. Kimmich 0, Molloy A, Whelan R, et al. Temporal discrimination, a cervical dystonia endophenotype: penetrance and functional correlates. Mov Disord 2014;29:804-811.

40. Ramos VF, Esquenazi A, Villegas MA, Wu T, Hallett M. Temporal discrimination threshold with healthy aging. Neurobiol Aging 2016;43:174-179.

41. Nielsen G, Buszewicz M, Stevenson F, et al. Randomised feasibility study of physiotherapy for patients with functional motor symptoms. J Neurol Neurosurg Psychiatry 2017;88:484-490. 


\section{DOCUMENTATION OF AUTHOR ROLES}

1. Research project: A. Conception, B. Organization, C. Execution;

2. Statistical Analysis: A. Design, B. Execution, C. Review and Critique;

3. Manuscript: A. Writing of the first draft, B. Review and Critique;

\section{AUTHORS CONTRIBUTION:}

FM: $1 \mathrm{~A}, 1 \mathrm{~B}, 2 \mathrm{~A}, 2 \mathrm{~B}, 2 \mathrm{C}, 3 \mathrm{~B}$

AM: 1B, 1C, 2B, 3A, 3B

$E A: 1 B, 1 C, 2 B, 3 A, 3 B$

LR: 2B, 2C, 3B

CA, CT: 1C, 3B

PG: 2C, 3B

MT: 1A, 3B 
Morgante et al, Pain processing in $C D$ and F-Dys

\section{FULL FINANCIAL DISCLOSURE FOR THE PREVIOUS 12 MONTHS}

\section{FM}

\begin{tabular}{|l|l|}
\hline Stock ownership in medically related fields & none \\
\hline Intellectual property rights & none \\
\hline Consultancies & Medtronic and Chiesi \\
\hline Expert testimony & none \\
\hline Advisory boards & none \\
\hline Employment & none \\
\hline Partnerships & none \\
\hline Contracts & none \\
\hline Honoraria & $\begin{array}{l}\text { UCB Pharma, Medtronic, Lundbeck, } \\
\text { Chiesi, Abbvie, Allergan, Merz }\end{array}$ \\
\hline Royalties & $\begin{array}{l}\text { FM receives royalties from Springer for } \\
\text { her book "Disorders of movement" }\end{array}$ \\
\hline Grants: & none \\
\hline Other & none \\
\hline
\end{tabular}

\section{LR}

\begin{tabular}{|l|l|}
\hline Stock ownership in medically related fields & none \\
\hline Intellectual property rights & none \\
\hline Consultancies & none \\
\hline Expert testimony & none \\
\hline Advisory boards & none \\
\hline Employment & none \\
\hline Partnerships & none \\
\hline Contracts & none \\
\hline Honoraria & Chiesi \\
\hline Royalties & none \\
\hline Grants: & none \\
\hline Other & none \\
\hline
\end{tabular}

AM, EA, CA, CT, PG, MT

\begin{tabular}{|l|l|}
\hline Stock ownership in medically related fields & none \\
\hline Intellectual property rights & none \\
\hline Consultancies & none \\
\hline Expert testimony & none \\
\hline Advisory boards & none \\
\hline Employment & none \\
\hline Partnerships & none \\
\hline Contracts & none \\
\hline Honoraria & none \\
\hline
\end{tabular}


Morgante et al, Pain processing in CD and F-Dys

\begin{tabular}{|l|l|}
\hline Royalties & none \\
\hline Grants: & none \\
\hline Other & none \\
\hline
\end{tabular}




\section{PAIN PROCESSING IN FUNCTIONAL AND IDIOPATHIC DYSTONIA: AN EXPLORATORY STUDY}

Francesca Morgante ${ }^{1,2}, \mathrm{MD}, \mathrm{PhD}$, Angela Matinella ${ }^{3}, \mathrm{MD}$, Elisa Andrenelli ${ }^{4}, \mathrm{MD}$, Lucia Ricciardi $^{2}, \mathrm{MD}, \mathrm{PhD}$, Cosimo Allegra ${ }^{1}, \mathrm{MD}$, Carmen Terranova ${ }^{1}, \mathrm{MD}, \mathrm{PhD}$, Paolo Girlanda ${ }^{1}, M D$, and Michele Tinazzi ${ }^{3}, M D$

${ }^{1}$ Department of Clinical and Experimental Medicine, University of Messina, Italy

${ }^{2}$ Institute of Molecular and Clinical Sciences, St George's University of London, London, United Kingdom

${ }^{3}$ Department of Neuroscience, Biomedicine and Movement, University of Verona, Italy

${ }^{4}$ Department of Experimental and Clinical Medicine, Università Politecnica delle Marche, Italy

Title (character count including spaces): 75

Running title: Pain processing in $\mathrm{CD}$ and F-Dys

Abstract count: 230; Text word count: 3134

Tables: 3; Figures: 2

Supplementary material: 1 table

References: 40

Key words: Functional movement disorders, psychogenic dystonia, cervical dystonia, pain, emotions

Financial disclosure related to research covered in this article: the authors do not have any funding source or any conflict of interest related to the research covered in the article.

\section{Correspondence to:}

Dr Francesca Morgante

Department of Clinical and Experimental Medicine, University of Messina, Italy 
Morgante et al, Pain processing in $C D$ and F-Dys

Email: fmorgante@gmail.com

\section{ABSTRACT}

\section{Background}

Pain is often experienced by patients with functional dystonia and idiopathic cervical dystonia and it is likely to be underlined by different neural mechanisms.

\section{Objective}

In this exploratory study, we tested the sensory-discriminative and cognitive-emotional component of pain in patients with functional and idiopathic dystonia.

\section{Methods}

Ten patients with idiopathic cervical dystonia, 12 patients with functional dystonia and 16 age- and gender matched healthy controls underwent psychophysical testing of tactile and pain thresholds and pain tolerance. We delivered electrical pulses of increasing intensity to the index finger of each hand and the halluces of each foot. Pain threshold and Pain tolerance were respectively defined as: 1) the intensity at which sensation changed from unpainful to faintly painfull and 2 ) the intensity at which painful sensation was intolerable.

\section{Results}

No differences were found between the three groups for tactile and pain thresholds assessed in both hands and feet. Pain tolerance was significantly increased in all body district only in functional dystonia. Patients with continuous functional dystonia had higher pain tolerance compared to subjects with paroxysmal functional dystonia and idiopathic cervical dystonia. Spearman Rank Correlation did not demonstrate any correlation between pain tolerance and pain scores, depression, anxiety, disease duration and motor disability in both groups.

\section{Conclusions}

Patients with functional dystonia have a dissociation between the sensory-discriminative and cognitive-emotional component of pain, as revealed by normal pain thresholds and increased pain tolerance. An abnormal connectivity between the motor and the limbic system might account for abnormal pain processing in functional dystonia. 


\section{INTRODUCTION}

Functional neurological disorders (FND) have been recently better defined at pathophysiological level and distinguished from symptoms that are intentionally produced, such as malingering and factitious disorder ${ }^{1}$. FND are a source of major neurological disability, especially when they produce a motor disturbance, such as in Functional Dystonia (F-Dys). Patients affected by F-Dys often experience pain, which is sometimes disproportionate to motor symptoms and it frequently occurs in body segments not affected by involuntary movements ${ }^{2}$. Subjects with idiopathic cervical dystonia also experience painful sensations, especially in affected body parts ${ }^{3}$.

The large brain network accessed during nociceptive processing is now commonly referred to as the "pain matrix" and it includes lateral (sensory-discriminatory) and medial (affective-cognitive) neuroanatomical components ${ }^{4}$. The lateral pathway projects to lateral thalamus and then to primary and secondary somatosensory areas, while the medial pathway projects to medial thalamic nuclei and limbic structures, such as the anterior cingulate cortex and the insular cortex. Sensory-discriminative and cognitive-affective aspects of pain may be selectively assessed by simple and reliable psycophysical parameters, such as the sensory thresholds. In particular, the pain threshold (P-Th) evaluates the sensory-discriminative component of pain, whereas the pain tolerance $(P$ tol) refers to the psychological perception of pain, a complex balance between cognitive and affective functions ${ }^{5}$. The contribution of the somatosensory system is well-known in idiopathic dystonia (including $C D)^{6}$ and it was recently demonstrated in functional dystonia (F-Dys), by testing of tactile temporal discrimination thresholds ${ }^{7}$. Yet, experimental data on pain perception are missing in both F-Dys and idiopathic cervical dystonia, which is often associated to pain. Only one study employing laser evoked potentials has revealed that the function of nociceptive pathways in cervical dystonia is comparable to healthy subjects $^{8}$.

Based on the evidence that in F-Dys there is an abnormal connectivity between motor and limbic areas ${ }^{9}$, we hypothesized an alteration of the cognitive-emotional component of pain in F-Dys. On the other hand, patients with idiopathic dystonia have an abnormal temporal processing of somatosensory stimuli ${ }^{10}$ and a distorsion of cortical maps in the somatosensory cortex ${ }^{11}$, which might determine an alteration of the sensory-discriminatory component of pain. Given these premises, in the present study we aimed to assess the sensory-discriminative and cognitive-emotional components of pain in idiopathic cervical 
Morgante et al, Pain processing in $C D$ and F-Dys

dystonia and F-Dys, testing pain thresholds and pain tolerance in affected and unaffected body segments.

\section{METHODS}

We enrolled 10 patients with idiopathic cervical dystonia (CD), 12 patients with clinically definite $\mathrm{F}$-Dys ${ }^{12}$ and 16 healthy controls $(\mathrm{HC})$ (13 females, 3 males; mean age = $34.6 \pm 10.8$ years).

The diagnosis of idiopathic dystonia was based on the Movement Disorders Society recommendations ${ }^{13}$ and the diagnosis of F-Dys on Gupta-Lang criteria ${ }^{12}$. Exclusion criteria were presence of clinically relevant cognitive impairment (MMSE <24), diabetes mellitus, tendon areflexia and polyneuropathy by nerve conduction studies. Severity of dystonia was evaluated with the Burke-Fahn-Marsden scale ${ }^{14}$ in all patients with F-Dys and CD. We also employed the Psychogenic Movement Disorders Rating Scale (PMDRS) ${ }^{15}$ in F-dys. In each patient, we retrieved demographical and clinical features (age at onset, disease duration, affected body districts).

Pain was assessed using the pain score of the Toronto Western Spasmodic Torticollis Rating Scale (TWSTRS) ${ }^{16}$. The TWSTRS includes pain scores for severity (0-10), duration (0-5) and pain-related disability (0-5). Moreover, all the different painful body segments were recorded, including those without dystonia. Depression and anxiety were evaluated in patients and controls with Hamilton depression Rating Scale (HAM-D) and Hamilton Anxiety Rating Scale (HAM-A). In all patients treated with botulinum toxin (BoNT), the experiment was carried out at least 3 months after the injection.

Tactile and pain thresholds were determined by the method of limits, according to a previous published protocol ${ }^{5,17}$. The stimulus consisted of a square wave electrical pulse of 0.2 ms delivered by a current stimulator (Digitimer D360, Digitimer Ltd, UK) through $\mathrm{AgCl}$ surface skin ring electrodes. The anode was located $1.5 \mathrm{~cm}$ distally from the cathode. Hands and feet were tested separately in a random order across patients. Electrical stimuli of increasing intensity were delivered to the little finger and big toe of both sides. In brief, the lowest intensity of stimulus $(0.5 \mathrm{~mA})$ was increased by $0.5 \mathrm{~mA}$ steps until the subject perceived the electrical stimulus (tactile threshold; T-Th). When the subject perceived the electrical stimulus, we delivered decreasing stimuli with minimum difference in intensity $(0.1 \mathrm{~mA})$ until the correct T-Th was determined. We considered as exact T-Th the value to which the subject gave the same affirmative answer after four consecutive stimuli at the same intensity. Then, the intensity of electrical stimulus was 
increased by $0.5 \mathrm{~mA}$ steps until the subject reported a change in sensation from unpainful to "faintly painful" (pain threshold, P-Th). The patient was asked to point out his pain intensity on a Visual Analogue Scale (VAS) line ranging from 0 to 10 . Finally, the intensity of electrical stimulus was increased by $1 \mathrm{~mA}$ steps until the subject reported an "intolerable" painful sensation (pain tolerance, P-Tol). If the subject did not report an intolerable pain sensation with $99 \mathrm{~mA}$ at $0.2 \mathrm{~ms}$ of stimulus duration, we increased the stimulus duration to $0.5 \mathrm{~ms}$ and $1 \mathrm{sec}$ ( 3 subjects with F-Dys described in the results).

In order to avoid the pain-modulating effects of BoNT injections, the experiments were performed with a distance after the last botulinum treatment of at least 3 months.

The study was approved by the ethic committee of University of Verona and conformed to the Declaration of Helsinki. All patients gave their written informed consent prior to participation.

\section{STATISTICAL ANALYSIS}

Normal distribution was checked using the Kolmogorov-Smirnov test. In case of deviation from normality, non-parametric tests were used.

Kruskal-Wallis test was employed to compare HC, F-Dys and CD for age and education level. Disease duration in F-Dys and CD was compared using the Mann-Whitney U test.

Differences in T-Th, P-Th and P-Tol among the 3 groups of subjects were explored by repeated measures analysis of variance (R-ANOVA) with "group" as between subjects factor (3 levels: HC, F-Dys and CD) and "side" (two levels: right, left) as within-subjects factor. The second aim of our study was to understand if pain thresholds were different in patients with F-Dys according to the temporal pattern of dystonic symptoms, namely patients with persistent versus paroxysmal symptoms. Accordingly, for each psychophysical variable (T-Th, P-Th and P-Tol), we run a separate R-ANOVA with "group" as between subjects factor (three levels: continuous F-Dys, paroxysmal F-Dys, CD) and "side" (two levels: right, left) as within-subjects factor.

Conditional on a significant F-value, post-hoc unpaired t-tests were performed to demonstrate differences between groups in each body site. Correction for multiple comparisons was not conducted given the exploratory nature of the study.

In F-Dys and CD, correlational analysis was performed by Spearman rank-correlation using P-tol values averaged between the right and left hand or foot. We verified whether $\mathrm{P}$-Tol values were correlated to age, age at onset, disease duration, BFM scale, pain scores of TWSTRS (severity, duration, disability due to pain), HAM-D and HAM-A. 
Morgante et al, Pain processing in $C D$ and F-Dys

Significance level was set at $p \leq 0.05$. Unless otherwise stated, data are given as mean \pm standard deviation (SD).

\section{RESULTS}

Distribution of gender was comparable among the 3 groups (G-squared p-value $=0.6$ ). Kruskall-Wallis analysis did not disclose any difference in age $(p=0.08)$, although patients with CD were older compared to $\mathrm{HC}(p=0.01)$. Age was comparable between $\mathrm{HC}$ and $\mathrm{F}$ dys $(p=0.5)$ and tended to be higher in CD compared to F-Dys $(p=0.06)$. All patients with CD and 4 out of 12 patients with F-Dys have been chronically treated with BoNT, performed at least 3 months before the experiment. Supplementary table online shows details on each patient's oral medications.

Tables 1 reports the features of patients with F-Dys and CD. At the time of the assessment, the two groups were comparable for age of onset ( $F-D y s=27.3 \pm 12.1$ years, $C D=37.5 \pm 15.8 ; p=0.5)$, disease duration $(p=0.7)$, level of anxiety $(p=0.9)$ and depression $(p=0.8)$. Among F-Dys, 4 patients had an exclusive involvement of facial muscles and the movement disorder was paroxysmal in 6 patients. The mean PMDRS score was 23.3+2.8. CD patients had isolated cervical dystonia, except for two patients who also presented writer's cramp.

The values of S-Th, P-Th and P-Tol in HC, CD, F-Dys recorded from the right and left hand and foot are displayed in table 2. For both S-Th and P-Th, R-ANOVA did not show any effect of the factor "group". No effect of group was found for pain intensity at pain threshold level by VAS (hands: $F_{2,35}=0.56, p=0.57$; feet: $F_{2,35}=1.31, p=0.29$ ). An effect of the factor "group" was found for P-Tol in both the hands $\left(F_{2,35}=3.766, p=0.033\right)$ and the feet $\left(F_{2,35}=3.986, p=0.028\right)$. No effect of the factor "side" (hands: $F_{2,35}=0.68, p=0.41$; feet: $F_{2,35}=0.16, p=0.70$ ) nor an interaction "side*group" (hand: $F_{2,35}=1.27, p=0.29$; feet: $F_{2,35}=0.02, p=0.99$ ) was found. Post-hoc analysis by unpaired t-test revealed a higher PTol in F-Dys compared to HC and CD, in the upper and lower limbs; no differences of PTol were found between CD and HC.

Figure 1 shows the individual values for P-Th and P-Tol in the 3 groups of subjects. For PTol, we had to increase the stimulus duration in 3 subjects with F-Dys who reported an unbearable stimulation at $0.5 \mathrm{~ms}$ (2 subjects for the right hand, right foot, left foot; 1 subject for the left hand) and 1 second (1 subject for all body districts.). As it was not possible to account for stimulus duration in the analysis only for 3 subjects, a value of 100 
$\mathrm{mA}$ (corresponding to the maximal allowed stimulation with $0.2 \mathrm{~ms}$ pulse width) was set as P-Tol in these subjects.

To understand if the increased P-Tol was influenced by the temporal course of functional dystonic manifestation (persistent or paroxysmal), we conducted a further analysis comparing CD patients to F-Dys with persistent (continuous F-Dys) and paroxysmal (paroxysmal F-Dys) functional symptoms. There was no main effect of the factor "group" both for S-Th in hands $\left(F_{2,19}=1.41, p=0.27\right)$ and feet $\left(F_{2,19}=2.11, p=0.16\right)$ and P-Th in hands $\left(F_{2,19}=0.82, p=0.45\right)$ and feet $\left(F_{2,19}=0.99, p=0.39\right)$. Neither a significant effect of "side" or an interaction "side* group" were found for S-Th and P-Th in the hands and feet.

For P-Tol, we found a "group" effect $\left(F_{2,19}=9.89\right.$; $\left.p=0.001\right)$, but neither an effect of "side" $\left(F_{2,19}=1.63 ; p=0.21\right)$ nor an interaction "side ${ }^{*}$ group" $\left(F_{2,19}=0.4 ; p=0.67\right)$. This effect was determined by a higher P-Tol in both hands and feet of F-Dys with continuous F-Dys compared to paroxysmal F-Dys and CD (Figure 2). Similar results for P-Tol were disclosed also in the lower limbs, as revealed by a main effect of "group" $\left(F_{2,19}=4.15 ; p=0.03\right)$ but neither an effect of "side" $\left(F_{2,19}=0.06 ; p=0.81\right)$ nor an interaction "side*group" $\left(F_{2,19}=0.01\right.$; $\mathrm{p}=0.98$ ) (Figure 2).

In CD and F-Dys, Spearman Rank Correlation did not show any correlation between P-tol in hands and feet with age, disease duration, pain scores of the TWSTRS, BFM, HDRS, HARS (Table 3). Only HDRS was correlated to pain severity score of the TWSTRS in FDys.

\section{DISCUSSION}

Painful sensory modalities have been poorly examined in idiopathic cervical dystonia and functional dystonia, two conditions characterized by pain, likely to be underlined by a different mechanism. Tactile and pain thresholds were comparable between F-Dys, CD and $\mathrm{HC}$, whereas pain tolerance was higher in F-Dys. This increase occured in both the upper and lower limbs only in subjects with persistent F-Dys, as paroxysmal F-Dys and idiopathic cervical dystonia had comparable pain tolerance.

Pain is a frequent feature associated to cervical dystonia, occurring in up to $88.9 \%$ of patients naïve to BoNT and being correlated with severity of dystonic symptoms ${ }^{3}$. Whether pain in cervical dystonia is related to chronic muscular contraction or is generated by an alteration of transmission and processing of nociceptive stimuli has been matter of debate for a long time ${ }^{8,18-20}$. Several sensory modalities have been explored in idiopathic isolated dystonia and one of the most frequently reported alteration is the prolonged temporal 
tactile discrimination threshold, which is a common feature to different types of dystonia, regardless the affected body segment ${ }^{21,22}$. Pain is a sensory modality, which is transmitted by $A-\delta$ and $C$ fibers and can be explored using a variety of stimuli, including pain thresholds evoked by thermal sensation and mechanical pressure. Electrical stimulation at high intensity as per pain threshold testing can stimulate small diameter, high threshold cutaneous afferents (A-delta) and even C-fibers ${ }^{23}$. When considering perception of mechanical painful stimuli, two studies on pain-pressure thresholds were conducted in CD with opposite results. An earlier study found reduced pain-pressure thresholds in 9 patients with CD (6 of them never treated with BoNT) compared to 5 healthy subjects ${ }^{19}$. However, when assessing a larger sample of 39 patients with CD, Kutvonen and coworkers found normal pain-pressure thresholds ${ }^{20}$. The normality of pain thresholds and tolerance in our CD sample parallels these early findings, obtained with pressure painful stimuli and supports the view that at least cutaneous nociceptive pathways are normal in patients with idiopathic CD chronically treated with BoNT. Overall, they are in keeping with the evidence that the amplitude of N2/P2 at laser evoked potential is comparable between CD and healthy subjects, regardless of stimulating a painful or painless area in dystonia ${ }^{8}$.

The abnormality of pain tolerance only in patients with persistent dystonic functional symptoms supports the recent view that there are distinct phenotypes among F-Dys ${ }^{24}$. However, data on pathophysiological differences among F-Dys phenotypes are not available. The increase of pain tolerance together with the normality of pain threshold, suggests a dissociation between the sensory-discriminative and cognitive-affective components of pain in persistent F-Dys. These two dimensions of pain are regulated by separate but parallel neural systems, respectively the lateral pain system (sensorydiscriminative dimension of pain) and the medial pain system (cognitive-affective dimension of pain $)^{25}$. The lateral system projects to the primary somatosensory cortex through the lateral thalamic nuclei whereas the medial system projects to several brain regions, including the cingulate cortex and limbic system, via the medial medial thalamic nuclei. The two systems are functionally segregated and can be separately assessed by applying nociceptive stimuli of different intensities ${ }^{26}$. The dissociation of the two systems in F-dys is in keeping with two previous studies, reporting increased pain tolerance and normal sensory-discriminative thresholds in patients with multisomatoform disorders ${ }^{27,} 28$. The category "somatoform" refers to DSM-IV TR, which included in this entity somatization and conversion disorder, pain, hypochondria and body dysmorphic disorder. Clinical 
features of subjects in these previous reports were not specified, therefore it is not possible to ascertain whether any functional movement disorder and more specifically functional dystonia was included. Nevertheless, both these studies reported averaged values from the right and the left hand and did not assess lower limbs.

Two psychological features of patients with FND might explain the increased pain tolerance in F-Dys: 1) the higher frequency of alexithymia, which refers to the inability to identify one's own emotions at a cognitive level $\left.{ }^{29} ; 2\right)$ the lower interoceptive awareness, which is predictive of their tendency to focus on the external features of their body ${ }^{30}$. A similar reduced interoceptive sensitivity was also found in somatoform patients who disclosed increased pressure-pain tolerance ${ }^{27}$.

A hypothesis to explain our findings in F-Dys is that the increased pain tolerance might be caused by abnormalities in limbic areas involved in emotion and pain processing (anterior cingulate cortex) and implicated in assigning emotional salience (amygdala, anterior insula, and posterior cingulate cortex). Indeed, abnormalities in areas involved in emotion recognition and processing has been shown in patients with FND ${ }^{31-33}$. Moreover, FND subjects have reduced activity and lower connectivity of the right temporoparietal junction (an area involved in generating an appropriate sensory prediction signal) with sensorimotor and limbic regions, such as the anterior cingulate cortex and right ventral striatum $^{32}$. Noteworthy, deep brain stimulation or lesioning of the anterior cingulate cortex are able to decrease the affective response to noxious stimuli and are employed to treat major depression or intractable pain ${ }^{34}$. This hypothesis needs confirmation by further studies emplying functional neuroimaging with pain stimuli tasks as well ass assessment of emotional processing and alexithymia.

When interpreting our results, we should also consider recent theories on FND ${ }^{35}$ postulating that two important mechanisms for generating these abnormal movements are self-focus attention and 'brain-expectations'. In fact, strong "top down" influences, such "prior beliefs" would tend to modify any "bottom up" sensory information. Moreover, excessive attention towards the body ${ }^{36}$ might underlie the decrease in externally directed attention. These could influence the cognitive appraisal of pain tolerance. However, this mechanism would not entirely explain the dissociation between pain threshold and tolerance in F-Dys.

Finally, chronic functional dystonia might have determined a reorganization of sensory areas, as it has been demonstrated in complex pain regional syndrome type I, a condition that should be included into the functional symptoms spectrum based on clinical and 
Morgante et al, Pain processing in $C D$ and F-Dys

neurophysiological evidence ${ }^{37}$. When dealing with pain it is also fundamental to discuss the role of emotions and mood on pain processing. Indeed, decreased pain thresholds and pain tolerances in Parkinson's disease were correlated to severity of depressive symptoms $^{5}$ and a similar association was found in patients with major depressive disorder ${ }^{17}$. Regarding the relationship between anxiety and pain tolerance, the literature has been controversial on this topic, with reports of decreased pain tolerance in posttraumatic stress disorder ${ }^{38}$ or lack of correlation between anxiety and pain tolerance in patients with juvenile fibromyalgia ${ }^{38}$. Accordingly, we screened our sample for depression and anxiety and we could not find any correlation with pain tolerance, which also had an inverse pattern in F-Dys compared to subjects with major depression. Yet, we need to recognize that we did not employ measures of state anxiety and depression that have been found to modulate pain perception.

We recognize that the small sample size of this exploratory study represents an important limitation, given the inter-subject variability of psychophysical data, especially in the lower limbs. Even though we could not find any correlation between age and pain tolerance in FDys, CD and HC, the role of age on pain tolerance should be specifically addressed in future studies, as it has been done for parameters of somatosensory processing, such as tactile temporal discrimination thresholds ${ }^{39,40}$. Moreover, objective measures such as pain evoked potentials or galvanic skin response should be added to P-Tol assessment in future studies investigating pain processing in functional dystonia. Chronic treatment with botulinum toxin and oral medication might also have interfered with pain thresholds testing, although they were equally distributed between patients' groups.

In conclusion, we reported a dissociation between the discriminative and affective dimension of pain in patients with persisten F-Dys, documented by a marked increase in pain tolerance in all body parts. Our data shed a light on the dissociation between pain perception and its emotional processing in patients with functional dystonia, which might be used to develop novel rehabilitation protocols, given the profound disability caused by pain and its negative impact on the selection for current physiotherapy protocols ${ }^{41}$. 


\section{LEGEND TO FIGURES}

Figure 1. Individual values for pain threshold and pain tolerance in functional dystonia (FDys) compared to idiopathic cervical dystonia (CD) and healthy controls (HC). CD = cervical dystonia; F-Dys= functional dystonia; $\mathrm{HC}=$ healthy controls; $\mathrm{PT}=$ pain threshold; $\mathrm{P}$-Tol = Pain tolerance. . Dotted and dashed lines respectively refer to the mean and standard deviation across the 3 groups.

Figure 2. Pain tolerance was significantly increased in the both hands of subjects with persistent functional dystonia (F-Dys-C) compared to paroxysmal functional dystonia (FDys-P) and cervical dystonia (CD). Pain tolerance was increased in both feet of F-Dys-C compared to CD; the difference between F-Dys-C and F-Dys-P did not reach statistical significance when considering P-Tol in both feet. 
Morgante et al, Pain processing in $C D$ and F-Dys

\section{REFERENCES}

1. Edwards MJ, Stone J, Lang AE. From psychogenic movement disorder to functional movement disorder: it's time to change the name. Mov Disord 2014;29:849-852.

2. Ganos C, Edwards MJ, Bhatia KP. The Phenomenology of Functional (Psychogenic) Dystonia. Movement Disorders Clinical Practice 2014;1:36-44.

3. Charles PD, Adler CH, Stacy M, et al. Cervical dystonia and pain: characteristics and treatment patterns from CD PROBE (Cervical Dystonia Patient Registry for Observation of OnabotulinumtoxinA Efficacy). J Neurol 2014;261:1309-1319.

4. Tracey I, Mantyh PW. The cerebral signature for pain perception and its modulation. Neuron 2007;55:377-391.

5. Zambito Marsala S, Tinazzi M, Vitaliani R, et al. Spontaneous pain, pain threshold, and pain tolerance in Parkinson's disease. J Neurol 2011;258:627-633.

6. Scontrini A, Conte A, Defazio G, et al. Somatosensory temporal discrimination in patients with primary focal dystonia. JNeurolNeurosurgPsychiatry 2009;80:1315-1319.

7. Morgante F, Tinazzi M, Squintani G, et al. Abnormal tactile temporal discrimination in psychogenic dystonia. Neurology 2011;77:1191-1197.

8. Tinazzi M, Valeriani M, Squintani G, et al. Nociceptive pathway function is normal in cervical dystonia: a study using laser-evoked potentials. J Neurol 2012;259:2060-2066.

9. Voon V, Brezing C, Gallea C, et al. Emotional stimuli and motor conversion disorder. Brain 2010;133:1526-1536.

10. Bradley D, Whelan R, Walsh R, et al. Temporal discrimination threshold: VBM evidence for an endophenotype in adult onset primary torsion dystonia. Brain 2009;132:2327-2335. 11. Meunier S, Garnero L, Ducorps A, et al. Human brain mapping in dystonia reveals both endophenotypic traits and adaptive reorganization. AnnNeurol 2001;50:521-527.

12. Gupta A, Lang AE. Psychogenic movement disorders. CurrOpinNeurol 2009;22:430436.

13. Albanese A, Bhatia K, Bressman SB, et al. Phenomenology and classification of dystonia: a consensus update. Mov Disord 2013;28:863-873.

14. Burke RE, Fahn S, Marsden CD, Bressman SB, Moskowitz C, Friedman J. Validity and reliability of a rating scale for the primary torsion dystonias. Neurology 1985;35:73-77. 15. Hinson VK, Cubo E, Comella CL, Goetz CG, Leurgans S. Rating scale for psychogenic movement disorders: scale development and clinimetric testing. Mov Disord 2005;20:15921597.

16. Comella CL, Stebbins GT, Goetz CG, Chmura TA, Bressman SB, Lang AE. Teaching tape for the motor section of the Toronto Western Spasmodic Torticollis Scale. Mov Disord 1997;12:570-575.

17. Zambito Marsala S, Pistacchi M, Tocco P, et al. Pain perception in major depressive disorder: a neurophysiological case-control study. J Neurol Sci 2015;357:19-21.

18. Stamelou M, Edwards MJ, Hallett M, Bhatia KP. The non-motor syndrome of primary dystonia: clinical and pathophysiological implications. Brain 2012;135:1668-1681.

19. Lobbezoo F, Tanguay R, Thon MT, Lavigne GJ. Pain perception in idiopathic cervical dystonia (spasmodic torticollis). Pain 1996;67:483-491.

20. Kutvonen O, Dastidar P, Nurmikko T. Pain in spasmodic torticollis. Pain 1997;69:279-

286.

21. Bradley D, Whelan R, Walsh R, et al. Comparing endophenotypes in adult-onset primary torsion dystonia. Mov Disord 2010;25:84-90.

22. Tinazzi M, Fiorio M, Fiaschi A, Rothwell JC, Bhatia KP. Sensory functions in dystonia: insights from behavioral studies. Mov Disord 2009;24:1427-1436. 
23. Lundberg LE, Jorum E, Holm E, Torebjork HE. Intra-neural electrical stimulation of cutaneous nociceptive fibres in humans: effects of different pulse patterns on magnitude of pain. Acta Physiol Scand 1992;146:41-48.

24. Petrovic IN, Tomic A, Voncina MM, Pesic D, Kostic VS. Characteristics of two distinct clinical phenotypes of functional (psychogenic) dystonia: follow-up study. J Neurol 2018;265:82-88.

25. Garland EL. Pain processing in the human nervous system: a selective review of nociceptive and biobehavioral pathways. Prim Care 2012;39:561-571.

26. Benedetti F, Vighetti S, Ricco C, et al. Pain threshold and tolerance in Alzheimer's disease. Pain 1999;80:377-382.

27. Weiss S, Sack M, Henningsen P, Pollatos O. On the interaction of self-regulation, interoception and pain perception. Psychopathology 2014;47:377-382.

28. Pollatos 0 , Dietel A, Herbert BM, et al. Blunted autonomic reactivity and increased pain tolerance in somatoform patients. Pain 2011;152:2157-2164.

29. Demartini B, Petrochilos P, Ricciardi L, Price G, Edwards MJ, Joyce E. The role of alexithymia in the development of functional motor symptoms (conversion disorder). J Neurol Neurosurg Psychiatry 2014;85:1132-1137.

30. Ricciardi L, Demartini B, Crucianelli L, Krahe C, Edwards MJ, Fotopoulou A. Interoceptive awareness in patients with functional neurological symptoms. Biol Psychol 2016;113:68-74.

31. Aybek S, Nicholson TR, O'Daly 0, Zelaya F, Kanaan RA, David AS. Emotion-motion interactions in conversion disorder: an FMRI study. PLoS One 2015;10:e0123273.

32. Voon V, Gallea C, Hattori N, Bruno M, Ekanayake V, Hallett M. The involuntary nature of conversion disorder. Neurology 2010;74:223-228.

33. Voon V, Brezing C, Gallea C, Hallett M. Aberrant supplementary motor complex and limbic activity during motor preparation in motor conversion disorder. Mov Disord 2011;26:2396-2403.

34. Boccard SGJ, Prangnell SJ, Pycroft L, et al. Long-Term Results of Deep Brain Stimulation of the Anterior Cingulate Cortex for Neuropathic Pain. World Neurosurg 2017;106:625-637. 35. Edwards MJ, Adams RA, Brown H, Parees I, Friston KJ. A Bayesian account of 'hysteria'. Brain 2012;135:3495-3512.

36. Edwards MJ, Fotopoulou A, Parees I. Neurobiology of functional (psychogenic) movement disorders. Curr Opin Neurol 2013;26:442-447.

37. Morgante F, Naro A, Terranova C, et al. Normal sensorimotor plasticity in complex regional pain syndrome with fixed posture of the hand. Mov Disord 2017;32:149-157. 38. King CD, Jastrowski Mano KE, Barnett KA, Pfeiffer M, Ting TV, Kashikar-Zuck S. Pressure Pain Threshold and Anxiety in Adolescent Females With and Without Juvenile Fibromyalgia: A Pilot Study. Clin J Pain 2017;33:620-626.

39. Kimmich 0, Molloy A, Whelan R, et al. Temporal discrimination, a cervical dystonia endophenotype: penetrance and functional correlates. Mov Disord 2014;29:804-811.

40. Ramos VF, Esquenazi A, Villegas MA, Wu T, Hallett M. Temporal discrimination threshold with healthy aging. Neurobiol Aging 2016;43:174-179.

41. Nielsen G, Buszewicz M, Stevenson F, et al. Randomised feasibility study of physiotherapy for patients with functional motor symptoms. J Neurol Neurosurg Psychiatry 2017;88:484-490. 


\section{DOCUMENTATION OF AUTHOR ROLES}

1. Research project: A. Conception, B. Organization, C. Execution;

2. Statistical Analysis: A. Design, B. Execution, C. Review and Critique;

3. Manuscript: A. Writing of the first draft, B. Review and Critique;

\section{AUTHORS CONTRIBUTION:}

FM: $1 \mathrm{~A}, 1 \mathrm{~B}, 2 \mathrm{~A}, 2 \mathrm{~B}, 2 \mathrm{C}, 3 \mathrm{~B}$

AM: 1B, 1C, 2B, 3A, 3B

$E A: 1 B, 1 C, 2 B, 3 A, 3 B$

LR: 2B, 2C, 3B

CA, CT: 1C, 3B

PG: 2C, 3B

MT: 1A, 3B 
Morgante et al, Pain processing in CD and F-Dys

\section{FULL FINANCIAL DISCLOSURE FOR THE PREVIOUS 12 MONTHS}

FM

\begin{tabular}{|l|l|}
\hline Stock ownership in medically related fields & none \\
\hline Intellectual property rights & none \\
\hline Consultancies & Medtronic and Chiesi \\
\hline Expert testimony & none \\
\hline Advisory boards & none \\
\hline Employment & none \\
\hline Partnerships & none \\
\hline Contracts & none \\
\hline Honoraria & $\begin{array}{l}\text { UCB Pharma, Medtronic, Lundbeck, } \\
\text { Chiesi, Abbvie, Allergan, Merz }\end{array}$ \\
\hline Royalties & $\begin{array}{l}\text { FM receives royalties from Springer for } \\
\text { her book "Disorders of movement" }\end{array}$ \\
\hline Grants: & none \\
\hline Other & none \\
\hline
\end{tabular}

LR

\begin{tabular}{|l|l|}
\hline Stock ownership in medically related fields & none \\
\hline Intellectual property rights & none \\
\hline Consultancies & none \\
\hline Expert testimony & none \\
\hline Advisory boards & none \\
\hline Employment & none \\
\hline Partnerships & none \\
\hline Contracts & none \\
\hline Honoraria & Chiesi \\
\hline Royalties & none \\
\hline Grants: & none \\
\hline Other & none \\
\hline
\end{tabular}

AM, EA, CA, CT, PG, MT

\begin{tabular}{|l|l|}
\hline Stock ownership in medically related fields & none \\
\hline Intellectual property rights & none \\
\hline Consultancies & none \\
\hline Expert testimony & none \\
\hline Advisory boards & none \\
\hline Employment & none \\
\hline Partnerships & none \\
\hline Contracts & none \\
\hline Honoraria & none \\
\hline
\end{tabular}


Morgante et al, Pain processing in CD and F-Dys

\begin{tabular}{|l|l|}
\hline Royalties & none \\
\hline Grants: & none \\
\hline Other & none \\
\hline
\end{tabular}




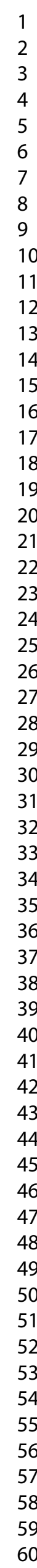

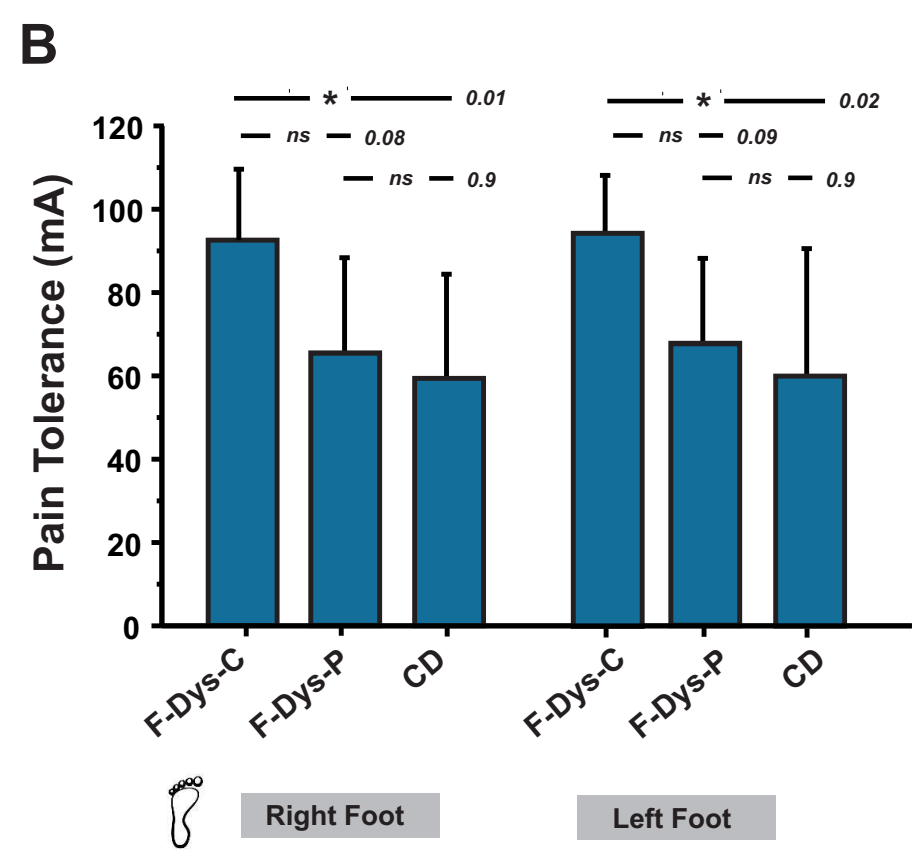


Table 1: Clinical features of patients affected by Functional and Idiopathic Cervical Dystonia

\begin{tabular}{|c|c|c|c|c|c|c|c|c|c|c|c|}
\hline $\mathbf{P t}$ & Gender & Age (y) & $\begin{array}{c}\text { Disease } \\
\text { duration (y) }\end{array}$ & $\begin{array}{l}\text { Affected Body } \\
\text { District }\end{array}$ & $\begin{array}{l}\text { BFM- } \\
\text { Mov }\end{array}$ & $\begin{array}{l}\text { BFM- } \\
\text { Dis }\end{array}$ & $\begin{array}{l}\text { Pain } \\
\text { score }\end{array}$ & $\begin{array}{c}\text { Pain } \\
\text { Duration" }\end{array}$ & $\begin{array}{c}\text { Pain } \\
\text { Disability }\end{array}$ & HARS & HDRS \\
\hline \multicolumn{12}{|c|}{$\begin{array}{l}\text { FUNCTIONAL DYSTONIA } \\
\end{array}$} \\
\hline 1 & $\mathrm{M}$ & 42 & 4 & Generalized - Px & 0 & 0 & 5.25 & 2 & 2 & 25 & 19 \\
\hline 2 & $\mathrm{~F}$ & 51 & 37 & Generalized - CT & 0 & 0 & 1.75 & 2 & 4 & 7 & 21 \\
\hline 3 & $\mathrm{~F}$ & 38 & 28 & Generalized - CT & 0 & 0 & 7.25 & 5 & 3 & 18 & 13 \\
\hline 4 & $\mathrm{M}$ & 43 & 22 & Generalized - CT & 0 & 0 & 2.75 & 2 & 2 & 18 & 12 \\
\hline 5 & $\mathrm{~F}$ & 58 & 15 & Neck+UL+trunk - Px & 12 & 11 & 8.5 & 3 & 2 & 45 & 23 \\
\hline 6 & $\mathrm{~F}$ & 25 & 6 & Neck + UL - CT & 5 & 1 & 3.25 & 5 & 2 & 6 & 11 \\
\hline 7 & $\mathrm{M}$ & 50 & 2 & Neck + trunk - CT & 18 & 4 & 2.5 & 2 & 2 & 5 & 9 \\
\hline 8 & $\mathrm{M}$ & 35 & 3 & Neck - CT & 7 & 4 & 4 & 2 & 1 & 11 & 15 \\
\hline 9 & $\mathrm{~F}$ & 37 & 1 & Face - Px & 0 & 4 & 5.25 & 2 & 2 & 8 & 13 \\
\hline 10 & $\mathrm{~F}$ & 23 & 0.6 & Face - Px & 1 & 8 & 5 & 4 & 4 & 22 & 21 \\
\hline 11 & $\mathrm{~F}$ & 36 & 9 & Face + UL-Tr - Px & 16 & 4 & 5 & 2 & 2 & 3 & 5 \\
\hline 12 & $\mathrm{~F}$ & 16 & 0.3 & Face + UL-Tr - Px & 8 & 4 & 6.75 & 5 & 2 & 18 & 19 \\
\hline $\begin{array}{l}\text { Mean } \\
\pm \text { SD }\end{array}$ & $4 \mathrm{M} / 8 \mathrm{~F}$ & $\begin{array}{c}37.8 \pm \\
12.2\end{array}$ & $\begin{array}{l}10.66 \\
\pm 12.2\end{array}$ & 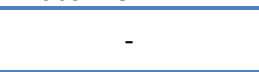 & $5.6 \pm 6.7$ & $3.3 \pm 3.5$ & $\begin{array}{c}4.8 \\
\pm 2.0\end{array}$ & $\begin{array}{c}3.0 \\
\pm 1.3\end{array}$ & $\begin{array}{c}2.3 \\
\pm 0.9\end{array}$ & $\begin{array}{r}15.5 \\
\pm 11.8\end{array}$ & $\begin{array}{l}15.1 \\
\pm 5.5\end{array}$ \\
\hline \multicolumn{12}{|c|}{ IDIOPATHIC CERVICAL DYSTONIA } \\
\hline 1 & $\mathrm{~F}$ & 37 & 3 & Neck - UL* & 6 & 4 & 4 & 10 & 5 & 4 & 8 \\
\hline 2 & $\mathrm{M}$ & 22 & 1 & Neck & 5 & 1 & 4 & 4 & 3 & 3 & 4 \\
\hline 3 & $\mathrm{~F}$ & 63 & 14 & Neck & 7 & 0 & 12 & 3.5 & 2 & 2 & 11 \\
\hline 4 & $\mathrm{~F}$ & 57 & 4 & Neck - UL* & 4 & 0 & 11 & 3.25 & 2 & 2 & 7 \\
\hline 5 & $\mathrm{~F}$ & 72 & 9 & Neck & 9 & 1 & 12 & 6 & 5 & 3 & 13 \\
\hline 6 & $\mathrm{~F}$ & 39 & 15 & Neck & 4 & 0 & 7 & 4.5 & 2 & 2 & 7 \\
\hline 7 & $\mathrm{~F}$ & 66 & 16 & Neck & 1.5 & 0 & 7 & 5 & 1 & 2 & 16 \\
\hline 8 & $M$ & 51 & 26 & Neck & 5 & 2 & 4 & 2.5 & 1 & 1 & 17 \\
\hline 9 & $\mathrm{~F}$ & 54 & 16 & Neck & 0.5 & 0 & 6 & 3.5 & 5 & 2 & 7 \\
\hline 10 & $M$ & 27 & 10 & Neck & 4 & 0 & 5 & 4 & 3 & 0 & 14 \\
\hline $\begin{array}{l}\text { Mean } \\
\pm \text { SD }\end{array}$ & $3 \mathrm{M} / 7 \mathrm{~F}$ & $\begin{array}{c}48.8 \\
\pm 16.9\end{array}$ & $\begin{array}{c}11.4 \\
7.6\end{array}$ & - & $\begin{array}{c}4.6 \\
\pm 2.5\end{array}$ & $\begin{array}{c}0.8 \\
\pm 1.3\end{array}$ & $\begin{array}{c}7.2 \\
\pm 3.3\end{array}$ & $\begin{array}{c}3.9 \\
\pm 2.9\end{array}$ & $\begin{array}{c}2.6 \\
\pm 1.6\end{array}$ & $\begin{array}{c}2.0 \\
\pm 1.2\end{array}$ & $\begin{array}{l}10.4 \\
\pm 4.4\end{array}$ \\
\hline p-value & & 0.06 & 0.4 & - & 0.7 & 0.06 & 0.6 & 0.8 & 0.7 & ${ }^{*} 0.0001$ & 0.06 \\
\hline
\end{tabular}

BFM-Mov= Burke Fahr Marsden Movement scale; BFM-Dis= Burke Fahr Marsden Disability scale; CT = Continuous; F=female; HARS= Hamilton Anxiety Rating

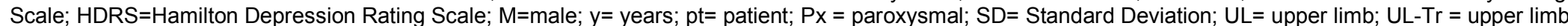
tremor. * Writer's cramp. "Pain sub-scores from the Toronto Western Spasmodic Torticollis Rating Scale (version 1). Comparisons by Mann-Whitney $U$ test. 
Table 2: Tactile and Pain Thresholds in Functional and Cervical Idiopathic Dystonia and Healthy Controls

\begin{tabular}{|c|c|c|c|c|c|}
\hline & $\begin{array}{l}\text { Body } \\
\text { site }\end{array}$ & $\begin{array}{l}\text { Functional } \\
\text { Dystonia }\end{array}$ & $\begin{array}{l}\text { Idiopathic } \\
\text { Dystonia }\end{array}$ & $\begin{array}{l}\text { Healthy } \\
\text { controls }\end{array}$ & Main Effects, F-value, P-value \\
\hline \multirow{4}{*}{$\begin{array}{l}\text { TACTILE } \\
\text { THRESHOLD } \\
(\mathrm{mA})\end{array}$} & $\mathrm{RH}$ & $2.03 \pm 0.58$ & $1.573 \pm 0.45$ & $1.67 \pm 0.41$ & \multirow{2}{*}{$\begin{array}{l}\text { Group: } F_{2,35}=2.012 ; p=0.1494 \\
\text { Side: } F_{2,35}=1.614 ; p=0.2125 \\
\text { Group*side: } F_{2,35}=1.953 ; p=0.1574\end{array}$} \\
\hline & LH & $1.93 \pm 0.41$ & $1.816 \pm 0.37$ & $1.78 \pm 0.33$ & \\
\hline & RF & $7.15 \pm 4.2$ & $5.862 \pm 1.35$ & $5.01 \pm 1.05$ & \multirow{2}{*}{$\begin{array}{l}\text { Group: } F_{2,35}=2.741 ; p=0.0807 \\
\text { Side: } F_{2,35}=1.638 ; p=0.2105 \\
\text { Group*side: } F_{2,35}=0.524 ; p=0.5977\end{array}$} \\
\hline & LF & $6.19 \pm 1.50$ & $5.397 \pm 1.38$ & $4.98 \pm 1.49$ & \\
\hline \multirow{4}{*}{$\begin{array}{l}\text { PAIN } \\
\text { THRESHOLD } \\
\text { (mA) }\end{array}$} & $\mathrm{RH}$ & $20.96 \pm 23.64$ & $8.55 \pm 5.56$ & $10.53 \pm 3.39$ & \multirow{2}{*}{$\begin{array}{l}\text { Group: } F_{2,35}=1.171 ; p=0.3219 \\
\text { Side: } F_{2,35}=1.126 ; p=0.2959 \\
\text { Group*side: } F_{2,35}=2.125 ; p=0.1346\end{array}$} \\
\hline & LH & $17.12 \pm 14.63$ & $19.38 \pm 8.74$ & $12.31 \pm 5.86$ & \\
\hline & RF & $41.97 \pm 21.27$ & $31.73 \pm 1.60$ & $28.78 \pm 11.42$ & \multirow{2}{*}{$\begin{array}{l}\text { Group: } F_{2,35}=2.084 ; p=0.1416 \\
\text { Side: } F_{2,35}=1.552 ; p=0.2222 \\
\text { Group }{ }^{*} \text { side: } F_{2,35}=1.361 ; p=0.2712\end{array}$} \\
\hline & LF & $41.88 \pm 20.31$ & $41.12 \pm 6.46$ & $29.12 \pm 10.69$ & \\
\hline \multirow{4}{*}{$\begin{array}{l}\text { PAIN } \\
\text { TOLERANCE } \\
\text { (mA) }\end{array}$} & $\mathrm{RH}$ & $66.8 \pm 38.09$ & $36.26 \pm 35.22$ & $32.97 \pm 23.79$ & \multirow{2}{*}{$\begin{array}{l}\text { Group: } F_{2,35}=3.766 ; p=0.033 \\
\text { Side: } F_{2,35}=0.68, p=0.41 \\
\text { Group*side: } F_{2,35}=1.27, p=0.29\end{array}$} \\
\hline & LH & $59.88 \pm 33.27$ & $34.10 \pm 29.04$ & $35.60 \pm 28.06$ & \\
\hline & RF & $79.05 \pm 25.25$ & $58.97 \pm 24.82$ & $60.12 \pm 18.53$ & \multirow{2}{*}{$\begin{array}{l}\text { Group: } F_{2,35}=3.986, p=0.028 \\
\text { Side: } F_{2,35}=0.16, p=0.70 \\
\text { Group side: } F_{2,35}=0.02, p=0.99\end{array}$} \\
\hline & LF & $80.41 \pm 23.74$ & $59.50 \pm 31.03$ & $60.70 \pm 18.84$ & \\
\hline
\end{tabular}

LF= Left Foot; $\mathrm{LH}=$ Left Hand; RF= Right Foot; RH= Right Hand 
Table 3: Correlations between pain tolerance and demographic and clinical data in Functional and Cervical Idiopathic Dystonia

\begin{tabular}{|c|c|c|c|c|c|c|c|c|c|}
\hline & Age & $\begin{array}{l}\text { Disease } \\
\text { duration }\end{array}$ & $\begin{array}{l}\text { P-Tol } \\
\text { hand }\end{array}$ & $\begin{array}{l}\text { P-Tol } \\
\text { foot }\end{array}$ & $\begin{array}{l}\text { Pain } \\
\text { severity }\end{array}$ & $\begin{array}{l}\text { Pain } \\
\text { duration }\end{array}$ & $\begin{array}{l}\text { Pain } \\
\text { disability }\end{array}$ & BFM & HDRS \\
\hline \multicolumn{10}{|c|}{ Functional Dystonia } \\
\hline Disease duration & .52 & & & & & & & & \\
\hline P-Tol hand & .39 & .48 & & & & & & & \\
\hline P-Tol foot & .18 & .23 & $.78^{* *}$ & & & & & & \\
\hline Pain severity & -.15 & -.23 & -.44 & -.38 & & & & & \\
\hline Pain duration" & -.47 & -.21 & -.1 & -.05 & .48 & & & & \\
\hline Pain disability" & .11 & .09 & -.02 & .01 & -.05 & .30 & & & \\
\hline$B F M$ & -.11 & -.28 & .07 & .14 & .01 & .06 & -.40 & & \\
\hline HDRS & -.08 & -.19 & -.52 & -.10 & $.63^{*}$ & .30 & -.18 & -.20 & \\
\hline HARS & .18 & .02 & -.40 & -.28 & .58 & .25 & -.30 & -.38 & $.89^{* *}$ \\
\hline & Age & $\begin{array}{l}\text { Disease } \\
\text { duration }\end{array}$ & $\begin{array}{l}\text { P-Tol } \\
\text { hand }\end{array}$ & $\begin{array}{l}\text { P-Tol } \\
\text { foot }\end{array}$ & $\begin{array}{l}\text { Pain } \\
\text { severity }\end{array}$ & $\begin{array}{l}\text { Pain } \\
\text { duration }\end{array}$ & $\begin{array}{l}\text { Pain } \\
\text { disability }\end{array}$ & BFM & HDRS \\
\hline \multicolumn{10}{|c|}{ Cervical Dystonia } \\
\hline Disease duration & .35 & & & & & & & & \\
\hline P-Tol hand & -.25 & -.09 & & & & & & & \\
\hline$P$-Tol foot & -.22 & -.22 & .19 & & & & & & \\
\hline Pain severity" & .28 & -.16 & -.15 & -.07 & & & & & \\
\hline Pain duration" & & & -67 & .54 & .62 & & & & \\
\hline Pain disability" & & & -.04 & .57 & $.73^{*}$ & -.53 & & & \\
\hline$B F M$ & .15 & -.44 & -.33 & .61 & .34 & .56 & .47 & & \\
\hline HDRS & .38 & -.03 & -.45 & -.16 & .51 & .24 & -.26 & .27 & \\
\hline HARS & .36 & .55 & .06 & -.32 & .36 & -.38 & -.46 & .12 & .51 \\
\hline
\end{tabular}

BFM-Mov= Burke Fahr Marsden scale; HARS= Hamilton Anxiety Rating Scale; HDRS=Hamilton Depression Rating Scale; "Pain sub-scores from the Toronto Western Spasmodic Torticollis Rating Scale (version 1). Values are Spearman's rho; ${ }^{*} p<0.05,{ }^{* *} p<0.01$ 


\section{Supplementary Table. Concomitant medication in Functional and Idiopathic Cervical Dystonia}

\begin{tabular}{|c|c|c|c|c|}
\hline $\mathbf{P t}$ & Gender & Age (y) & Affected Body District & Medication \\
\hline \multicolumn{5}{|c|}{ Functional Dystonia } \\
\hline 1 & M & 42 & Generalized - Px & $\begin{array}{c}\text { Botulinum Toxin } \\
\text { Duloxetine } 30 \mathrm{mg} / \text { daily } \\
\text { Clonazepam } 2 \mathrm{mg} / \text { daily }\end{array}$ \\
\hline 2 & $\mathrm{~F}$ & 51 & Generalized - CT & $\begin{array}{c}\text { Botulinum Toxin } \\
\text { Escitalopram } 10 \mathrm{mg} / \text { daily } \\
\text { Clonazepam } 2 \mathrm{mg} / \text { daily }\end{array}$ \\
\hline 3 & $\mathrm{~F}$ & 38 & Generalized - CT & - \\
\hline 4 & $M$ & 43 & Generalized - CT & - \\
\hline 5 & $\mathrm{~F}$ & 58 & Neck+UL+ trunk - Px & $\begin{array}{c}\text { Botulinum Toxin } \\
\text { Lorazepam } 1 \text { mg/daily }\end{array}$ \\
\hline 6 & $\mathrm{~F}$ & 25 & Neck + UL - CT & $\begin{array}{c}\text { Botulinum Toxin } \\
\text { Clonazepam } 1 \mathrm{mg} / \text { daily }\end{array}$ \\
\hline 7 & $\mathrm{M}$ & 50 & Neck + trunk - CT & - \\
\hline 8 & $M$ & 35 & Neck - CT & Paroxetine 10 mg/daily \\
\hline 9 & $\mathrm{~F}$ & 37 & Face - Px & - \\
\hline 10 & $\mathrm{~F}$ & 23 & Face - Px & - \\
\hline 11 & $\mathrm{~F}$ & 36 & Face + UL-Tr - Px & Clonazepam 2 mg/daily \\
\hline 12 & $\mathrm{~F}$ & 16 & Face + UL-Tr - Px & Clonazepam 1 mg/daily \\
\hline \multicolumn{5}{|c|}{ Idiopathic Cervical Dystonia } \\
\hline 1 & $\mathrm{~F}$ & 37 & Neck $-U^{*}$ & Botulinum toxin \\
\hline 2 & M & 22 & Neck & $\begin{array}{c}\text { Botulinum toxin } \\
\text { Clonazepam } 2 \mathrm{mg} / \text { daily }\end{array}$ \\
\hline 3 & $\mathrm{~F}$ & 63 & Neck & Botulinum toxin \\
\hline 4 & $\mathrm{~F}$ & 57 & Neck - UL* & $\begin{array}{c}\text { Botulin toxin } \\
\text { Clonazepam } 3 \mathrm{mg} / \text { daily }\end{array}$ \\
\hline 5 & $\mathrm{~F}$ & 72 & Neck & Botulinum toxin \\
\hline 6 & $\mathrm{~F}$ & 39 & Neck & Botulinum toxin \\
\hline 7 & $\mathrm{~F}$ & 66 & Neck & $\begin{array}{c}\text { Botulinum toxin } \\
\text { Lorazepam } 1 \mathrm{mg} / \text { daily }\end{array}$ \\
\hline 8 & M & 51 & Neck & $\begin{array}{c}\text { Botulinum toxin } \\
\text { Escitalopram } 10 \mathrm{mg} / \text { daily }\end{array}$ \\
\hline 9 & $\mathrm{~F}$ & 54 & Neck & $\begin{array}{c}\text { Botulinum toxin } \\
\text { Paroxetine } 20 \mathrm{mg} / \text { daily }\end{array}$ \\
\hline 10 & M & 27 & Neck & $\begin{array}{c}\text { Botulinum toxin } \\
\text { Clonazepam } 2 \mathrm{mg} / \text { daily }\end{array}$ \\
\hline
\end{tabular}

$\mathrm{CT}=$ Continuous; $\mathrm{Px}=$ paroxysmal; UL= upper limb; UL-Tr = upper limb tremor. * Writer's cramp 